difficult manipulative procedures when there is always the risk of a claim for heavy damages should anything "go wrong."

Caesarean section rates in breech delivery do vary from hospital to hospital, and, indeed, from country to country, and for reasons that are plain to see. The management of breech birth is affected by such factors as the age, parity, and nutritional state of the pregnant women (and to some extent by the preference the women themselves have for either abdominal or vaginal delivery), the experience and skill of the obstetrician, and whether he has the immediate support of paediatricians and nurses in a neonatal intensive care unit. A further, and important, consideration is the local practice in regard to litigation.

There can, therefore, be no universally applicable agreed correct or optimum caesarean section rate for breech birth. But it is time to take stock, to look at some of the implications of this widespread trend towards abdominal delivery in breech birth. The higher the incidence of elective abdominal delivery the less chance there is for resident staff to gain experience of all the subtle observations and skills associated with the safe management of vaginal breech birth. This in time will lead to an even higher caesarean section rate, for future obstetricians will probably turn to the easier technique of caesarean section in preference to risking the hazards of a vaginal breech birth for which they are poorly trained. Another concern is the increasing acceptance of caesarean section for impending preterm breech delivery. This has been ably discussed recently by Crowley and Hawkins. ${ }^{7}$ From their critical examination of 11 papers published since 1975 they conclude that abdominal delivery appears to be advantageous for the infant weighing between 1000 and $1500 \mathrm{~g}$ but that operative delivery is much more difficult to justify for babies weighing less than $1000 \mathrm{~g}$. Caesarean delivery should be considered when the child can be cared for immediately in a specialist neonatal intensive care unit. With breech babies of this gestational age and weight there is a substantial risk of some major congenital anomaly, ${ }^{8-12}$ and even when adequate screening procedures have been carried out the obstetrician undertaking caesarean section can never be sure that he will be spared the embarrassment of delivering a small baby with some deformity that will prove fatal within days or weeks.

Mostly the operation chosen is a lower-segment caesarean section, but at an early gestational age some obstetricians prefer a classical section. ${ }^{9}$ This issue has been little discussed, but should the present tendency towards caesarean section for preterm breech birth continue it should receive more attention. Classical section is a bad operation with increased immediate and long-term risks for the mother. Indeed, the whole matter of risk for the mother is something that must be considered carefully as the rate of abdominal breech birth increases. No direct comparison can be made between the risks associated with vaginal and abdominal delivery in breech presentation, but abdominal delivery must increase the threat to the life of the mother severalfold, ${ }^{13-15}$ and both immediate and long-term morbidity are also increased.

Previous leading articles ${ }^{16-18}$ have reviewed particular aspects of breech birth, but the central controversial issue is the balance between vaginal and abdominal delivery. Obstetricians seem steadily to be moving towards a policy of abdominal delivery, but this may well be challenged-in the same way that high rates of induction of labour and of episiotomy have been challenged in recent years.

Professor of Obstetrics and Gynaecology,

J K RuSSELL

Princess Mary Maternity Hospital,

Newcastle upon Tyne NE2 3BD
1 Moir JC, Myerscough PR, eds. Munro Kerr's operative obstetrics. 8th ed. London: Baillière, Tindall and Cassell, 1971.

Dewhurst J. Integrated obstetrics and gynaecology for postgraduates. 3rd ed. London: Blackwell Scientific Publications, 1981.

National Institutes of Health. Cesarean childbirth-report of a consensus development conference. Bethesda, Maryland: National Institutes of Health, 1980.

' Quilligan EJ, Zuspan FP, eds. Douglas-Stromme operative obstetrics. 4th ed. New York: Appleton-Century-Crofts, 1982.

Pritchard JA, MacDonald PC, eds. Williams' obstetrics. 16th ed. New York: Appleton-Century-Crofts, 1980

" de Groot HA. Annual report. Cape Town: Department of Obstetrics and Gynaecology, University of Cape Town, 1980.

Crowley P, Hawkins DF. Premature breech delivery-the caesarean section debate. Fournal of Obstetrics and Gynaecology 1980;1:2-6.

* Brenner WE, Bruce RD, Hendricks CH. The characteristics and perils of breech presentation. Am F Obstet Gynecol 1974;118:700-12.

${ }^{9}$ Braun FHT, Jones KL, Smith DW. Breech presentations as an indicator of fetal abnormality. $\mathcal{F}$ Pediatr $1975 ; 86: 419-21$.

11) Geirsson RT, Namunkangula R, Calder AA, Lunan CB. Preterm singleton breech presentation: the impact of traumatic intracranial haemorrhage on neonatal mortality. Fournal of Obstetrics and Gynaecology 1982;2: 219-23.

11 Karp LE, Doney JR, McCarthy T, Meis PJ, Hall M. The premature breech: trial labor or cesarean section ? Obstet Gynecol 1979;53:88-92.

12 Goldenberg RL, Nelson KG. The premature breech. Am $\mathcal{F}$ Obstet Gynecol $1977 ; 127: 240-4$

${ }^{13}$ Collea JV, Rabin SC, Weghorst GR, Quilligan EJ. The randomized management of term frank breech presentation: vaginal delivery vs cesarean section. Am $\mathcal{F}$ Obstet Gynecol 1978;131:186-95.

14 Collea JV, Chein C, Quilligan EJ. The randomised study of term frank breech presentation: a study of 208 cases. Am F Obstet Gynecol 1980; 137:235-44.

1.5 Francome C, Huntingford PJ, Births by caesarean section in the United States of America and in Britain. 7 Biosoc $S_{c i} 1980 ; 12: 353-62$.

${ }^{16}$ Anonymous. Fetal damage from breech birth. Br Med $\mathcal{F} 1975$;ii:158-9.

17 Anonymous. Birth trauma in vaginal breech delivery. Br Med $\mathcal{f} 1978$; : $320-1$.

1* Anonymous. Premature breech: vaginal delivery or caesarean section? Br Med F 1979; : 1747 .

\section{Management of pulmonary embolism}

As Bell and Simon have recently pointed out in a comprehensive review, ${ }^{1}$ pulmonary embolism is still an important cause of morbidity and death. Venous thrombosis and pulmonary embolism are sometimes preventable, as numerous clinical trials in patients having general surgical operations have shown; and limited epidemiological evidence shows a fall in incidence in general surgical wards, possibly attributable to prophylactic measures. ${ }^{2}$ In other specialties, such as orthopaedics and neurosurgery, the problems of prophylaxis have not been entirely solved, particularly in cases of trauma. Specific prophylactic measures appear to have been applied in patients with medical conditions only after myocardial infarction ${ }^{3}{ }^{4}$ and stroke. ${ }^{5}$ With the recognition of predisposing factors (including previous thromboembolism, varicose veins, age, obesity, malignancy, and cardiac disease) selective prophylaxis should, perhaps, be used more often in acute medical wards.

As for established embolism, no dramatic improvements have been made in management in recent years, but the role of investigations have been more clearly defined and some treatments modified. Most pulmonary emboli are small; indeed, most do not cause infarction and are therefore silent. ${ }^{6}$ Even when symptoms do arise they are usually non-specific. Embolism may masquerade as pneumonia, congestive cardiac failure, myocardial infarction, chronic obstructive airways disease, angina, pleurisy, or carcinoma of the lung. ${ }^{7}$ Leg 
symptoms, if they occur at all, usually come after the lung symptoms. Bell, Simon, and De Mets ${ }^{8}$ have made a full analysis of the symptoms and signs.

Since venous thromboembolism is mainly a benign and selflimiting disease we can apply inactive or irrational management with apparent success, the infrequent death or chronically swollen leg being accepted as par for the course. It is a pity that the clinician who manages the patient with acute deep vein thrombosis or embolism seldom has to cope with chronic postthrombotic symptoms. Sometimes lives may be saved and morbidity reduced by vigorous treatment-and this and the fact that many lethal emboli are preceded by smaller "herald" emboli ${ }^{9}$ constitute the main arguments for an active approach to management. Furthermore, since anticoagulants may also cause death and morbidity, patients should be properly investigated before these are prescribed.

How, then, should pulmonary embolism be managed? There are two quite different approaches depending on the severity of the attack. For practical purposes pulmonary emboli may be divided into "big" and "small." A big embolism is one which threatens life. Its salient features are the sudden onset of central chest pain, dyspnoea, and hypotension, with or without cardiac arrest. Resuscitation is required, after which the investigations and treatment are directed primarily at the site of embolism, the lungs and heart. In contrast, a small embolism presents usually with haemoptysis, pleuritic chest pain, and little or no dyspnoea; not uncommonly the onset of symptoms is insidious. Investigations and treatment should be directed at the source of the embolism since it is the residual or recurrent peripheral thrombus that is the main threat to life.

When embolism is suspected, especially if it is a big one, oxygen and a large dose (such as 10000 international units) of intravenous heparin should be given right away. The differential diagnosis includes few conditions that could be aggravated by a single bolus of heparin. The object is to prevent additional accretion of thrombus. ${ }^{10} \mathrm{Next}$, intravenous fluids should be given to support right ventricular output and augment pulmonary blood flow for better oxygenation. Vasopressors, inotropic agents, antiarrhythmic drugs, and digitalis may be specifically indicated.

The next step, since the error rate is high, is to confirm the diagnosis. In the patient who is hyppotensive or shows signs of right ventricular strain, pulmonary angiography is the investigation of choice. The pulmonary artery catheter is left in situ to monitor pressure and as a convenient, though not essential, route for infusion of thrombolytic treatment. The United States national co-operative pulmonary embolism trial, ${ }^{11}$ in which 12 to 24 hours of urokinase or 24 hours of streptokinase were compared with heparin, did not show a benefit in mortality in the thrombolytic groups, which would have required larger numbers. It did, however, show a definite acceleration in angiographic resolution, improved perfusion by lung scan, lowering of pulmonary artery pressure, and improvement in measurements of both right and left heart function in the thrombolytic groups. Streptokinase is the cheaper and the dose is 250000 units over 30 minutes followed by 100000 units an hour for 24 hours. Pulmonary embolectomy need be considered only in the patient who deteriorates despite these measures. Further developments in thrombolytic treatment are likely, such as the combination of the lytic agent with plasminogen. ${ }^{12} \mathrm{~A}$ possible new dimension in treatment is offered by intervention radiology. Greenfield et al have reported the successful removal of thrombus from the pulmonary artery by a suction catheter inserted into a femoral vein. ${ }^{13}$

When embolism does not threaten life immediately the investigations of choice are phlebography and radioisotope lung scan, and these should be done within 24 hours of the diagnosis being suspected, the patient being maintained with intravenous heparin in the interim. Other investigations, such as electrocardiography, chest radiography, and blood gas measurements, may help but the results are non-specific.

Phlebography and lung scanning are performed to substantiate the diagnosis, guide treatment, and provide important baselines for later management. Though emboli may derive from the right heart, the internal iliac veins, and the neck and arm veins (increasingly as central lines are used), most still come from the leg veins. A good-quality bilateral ascending phlebogram which is completely clear of thrombus should cast serious doubt on the diagnosis and may allow, depending on the circumstances, the important bonus of withholding anticoagulants.

Much has been written about the lack of specificity of perfusion lung scanning. Nevertheless, the method remains the mainstay of diagnosis, since most hospitals do not have facilities for ventilation scans to enhance the scanning accuracy. True, many perfusion scans show non-segmental defects compatible with rather than diagnostic of pulmonary embolism. A negative scan result, however, is of great value, a clearly positive result equally so, and even the equivocal result may act as an invaluable baseline for follow-up examinations. The lung scan is important and enormously helpful if viewed critically.

In most instances the acute stage of thromboembolism is relatively easy to deal with. The difficult questions and decisions come later. Is the thrombus being controlled? Is the patient continuing to produce emboli? How long should the heparin be continued? Is it safe to mobilise the patient? Are oral anticoagulants required? If so, how long should they be continued? Logical answers to these questions are almost impossible if the baseline investigations have not been done. One can only generalise. My policy is to continue intravenous heparin by infusion pump for seven to 10 days-longer in severe cases. A more practical (since it allows the patient to get up) and equally effective alternative may be high-dose heparin by the subcutaneous route. ${ }^{14}$ Oral anticoagulants are not started until a second lung scan about a week after the first shows that no further embolism has occurred. Experience suggests that converting to oral anticoagulants too soon may lead to relapse with extension of the deep vein thrombosis or recurrent embolism. These problems may also occur when the patient starts walking. Oral anticoagulants should overlap with heparin by three to five days and be continued for a minimum of six months. Treatment should continue long term if the patient has postphlebitic symptoms, in which case highquality, carefully fitted, graduated elastic compression hosiery should also be prescribed. If anticoagulants are worth prescribing they are worth controlling carefully.

Venous interruption (such as caval plication or filter, or superficial femoral ligation) has a definite but very occasional place. The main indications are recurrent embolism despite well-controlled anticoagulation, and embolism or serious phlebographically proved thrombus in a patient in whom anticoagulation is contraindicated. Any surgeon carrying out a major abdominal operation in a patient with a well-documented history of thromboembolism is advised to place a corrugated clip (Miles) around the infrarenal cava. ${ }^{15}$

C V RUCKLEY

Consultant Surgeon,

Royal Infirmary,

Edinburgh EH3 9YW 
' Bell WR, Simon TL. Current status of pulmonary thromboembolic disease: pathophysiology, diagnosis, prevention, and treatment. $A m$ Heart $\mathcal{F} 1982 ; 103: 239-62$.

2 Ruckley CV, Thurston C. Pulmonary embolism in surgical patients: 1959-1979. Br Med f 1982;284:1100-3.

${ }^{3}$ Handley AJ. Low dose heparin after myocardial infarction. Lancet 1972; ii :623-4

- Warlow C, Terry G, Kenmure ACF, Beattie AG, Ogston D, Douglas AS. A double blind trial of low doses of subcutaneous heparin in the prevention of deep vein thrombosis after myocardial infarction. Lancet 1973; ii:934-6.

${ }^{5}$ McCarthy ST, Robertson D, Turner JJ, Haekey CJ, Macey DJ. Low-dose heparin as a prophylaxis against deep-vein thrombosis after acute stroke. Lancet 1977; ii:800-1.

${ }^{6}$ Hume M, Sevitt S, Thomas DP. Venous thrombosis and pulmonary embolism. Cambridge, Mass: Harvard University Press, 1970.

' Sasahara AA, Cannilla JE, Morse RL, Sidd JJ, Tremblay GM. Clinical and physiologic studies in pulmonary thromboembolism. $\mathrm{Am} \mathcal{F} \mathrm{Cardiol}$ 1967;20:10-20.

8 Bell WR, Simon TL, De Mets DL. The clinical features of submassive and massive pulmonary emboli. Am f Med 1977;62:355-60.

9 Belt TH. Thrombosis and pulmonary embolism. Am $\mathcal{F}$ Pathol 1934;10: 129-44.

10 Deykin D. Current concepts: the use of heparin. $N$ Engl f Med $1969 ; 280$ : 937-8.

11 Urokinase Pulmonary Embolism Study Group. Urokinase-streptokinase embolism trial. Phase 2 results. A cooperative study. F $A M A 1974 ; 229$ : 1606-13.

12. Smith RAG, Dupe RJ, English PD, Green J. Fibrinolysis with acylenzymes: a new approach to thrombolytic therapy. Nature $1981 ; 290$ : 505-8.

13 Greenfield LJ, Bruce TA, Nichols NB. Transvenous pulmonary embolectomy by catheter device. Ann Surg 1971;174:881-6.

14 Bentley PG, Kakkar VV, Scully MF, et al. An objective study of alternative methods of heparin administration. Thromb Res 1980;18:177-87.

${ }^{15}$ Miles RM, Chappell F, Renner O. A partially occluding vena caval clip for prevention of pulmonary embolism. Am Surg 1964;30:40-7.

\section{Hepatic granulomas}

Granulomas are focal accumulations of modified macrophages. They are thought to form when macrophages ingest poorly soluble antigens. These can be viral, bacterial, fungal, parasitic, or unrelated to infection or infestation, so that when granulomas are found in the liver many different causes have to be considered. ${ }^{1-6}$ Sarcoidosis and tuberculosis are high on the list in many series.

When liver biopsies are done in the course of investigation of systemic symptoms such as fever or loss of weight granulomas may be the principal or only histological abnormality. Clinician and pathologist must then set up series of further investigations until the cause is found. Alternatively, the pathologist may find one or more granulomas in a biopsy specimen showing changes of underlying liver disease. The granulomas may then help to establish the nature of this disease, as in primary biliary cirrhosis, in which granulomas are common in the early stages. ${ }^{7}$ In other instances the granulomas, while not contributing to the diagnosis, are readily explained; for example, granulomas form in fatty livers when fat-laden liver cells rupture. ${ }^{2}$ Sometimes granulomas seen in liver disease cannot be explained, and then it is prudent to try to exclude important causes such as tuberculosis, sarcoidosis, and brucellosis. Prolonged, exhaustive investigation is not, however, usually indicated.

To the pathologist hepatic granulomas fall into three groups. In the first the cause is seen under the microscope. Examples include granulomas forming around ova of Schistosoma mansoni and tuberculous lesions containing detectable tubercle bacilli. Unfortunately, few granulomas are so easily explained in Western countries, and even in proved tuberculosis bacilli are often not found histologically. ${ }^{146}$ In the second group the cause is not seen, but histological features of the granulomas themselves or of the associated liver disease strongly suggest the diagnosis. Examples are extensive caseous necrosis in tuberculosis and granulomas near damaged bile ducts in a biopsy specimen showing other features of primary biliary cirrhosis. A recently recognised member of this group of granulomas with helpful diagnostic features is the lesion of $Q$ fever: in some patients with this disease liver biopsy shows a distinctive pattern of epithelioid cells, segmented leucocytes, and fibrin surrounding fat vacuoles. ${ }^{8}{ }^{9}$ Histological characteristics are occasionally misleading, as in the rare instances of granulomas in sarcoidosis undergoing extensive necrosis. When histological features suggest but do not prove the diagnosis serological or microbiological confirmation is desirable.

In the third and last, unfortunately large, group the cause of the granulomas cannot be established with any degree of certainty, though there may be histological clues which help narrow the field and suggest a rational sequence of further investigation. An important cause of unexplained granulomas is drug hypersensitivity. McMaster and Hennigar ${ }^{5}$ attributed 28 of 95 examples of hepatic granulomas to therapeutic drugs, several of them in common use such as sulphonamides and methyldopa. Most patients had fever and hepatomegaly, and some had peripheral eosinophilia. Histologically the lesions were both portal and intralobular, eosinophils were common, and in some biopsy specimens granulomas were located near damaged small bile ducts.

When all likely causes of granulomas have been excluded with reasonable certainty clinically and histologically a group of puzzling patients remains. In Klatskin's large series of 565 patients with hepatic granulomas, ${ }^{4}$ no diagnosis could be established in 37. Nearly half of these had a prolonged feverish illness. Simon and Wolff ${ }^{10}$ have described an idiopathic granulomatous hepatitis characterised by prolonged or recurrent fever, often with loss of weight, myalgia, arthralgia, or abdominal pain. Most patients failed to respond to a trial of antituberculous drugs but subsequently improved with corticosteroids. Though different and as yet undefined causes may contribute to this kind of illness, it is perhaps among the few for which the poorly defined term granulomatous hepatitis is appropriate. Possibly some such patients may have the polymyalgia rheumatica and giant-cell arteritis syndrome without clinical evidence of temporal arteritis. ${ }^{11}$

Granulomas in a liver biopsy specimen may have prognostic as well as diagnostic implications. In a series of 100 patients with primary biliary cirrhosis ${ }^{7}$ granulomas were found less often in patients who subsequently died than in the survivors. Granulomas should therefore be taken into account in assessing the results of therapeutic trials in this disease. The relation between granuloma formation and clinical course needs confirmation and explanation, but it is in keeping with the known favourable prognostic implication of granulomas in other diseases such as Hodgkin's lymphoma and Crohn's disease.

\section{Peter J SCHEUER}

Professor of Clinical Histopathology,

Royal Free Hospital and School of Medicine, London NW3 2QG

${ }^{1}$ Guckian JC, Perry JE. Granulomatous hepatitis. An analysis of 63 cases and review of the literature. Ann Intern Med 1966;65:1081-100.

2 Iversen K, Christoffersen P, Poulsen $\mathbf{H}$. Epithelioid cell granulomas in liver biopsies. Scand $\mathcal{F}$ Gastroenterol 1970;suppl 7:61-7.

${ }^{3}$ Neville E, Piyasena KHG, James DG. Granulomas of the liver. Postgrad Med f 1975;51:361-5.

4 Klatskin G. Hepatic granulomata: problems in interpretation. Ann NY Acad Sci 1976;278:427-32. 